\title{
Anticoagulant treatment in primary health care in Sweden - prevalence, incidence and treatment diagnosis: a retrospective study on electronic patient records in a registered population Gunnar H Nilsson*1, Ingela Björholt ${ }^{2}$ and Hans Johnsson ${ }^{3}$
}

Address: ${ }^{1}$ Department of Medicine, Research Unit of General Practice, Karolinska Institutet, Stockholm, Sweden, ${ }^{2}$ AstraZeneca Sverige AB, Mölndal, Sweden and ${ }^{3}$ Emergency Clinic, Karolinska hospital, Stockholm, Sweden

Email: Gunnar H Nilsson* - gunnar.nilsson@nlpo.sll.se; Ingela Björholt - ingela.bjorholt@astrazeneca.com;

Hans Johnsson - hans.johnsson@ks.se

* Corresponding author

Published: I April 2003

BMC Family Practice 2003, 4:3
Received: 21 January 2003

Accepted: I April 2003

This article is available from: http://www.biomedcentral.com/l47/-2296/4/3

(c) 2003 Nilsson et al; licensee BioMed Central Ltd. This is an Open Access article: verbatim copying and redistribution of this article are permitted in all media for any purpose, provided this notice is preserved along with the article's original URL.

\begin{abstract}
Background: The indications for warfarin treatment in primary health care are increasing. An undertreatment with warfarin is reported in the prevention of embolic stroke in patients with chronic atrial fibrillation, and can be suspected for other indications. Information on the prevalence and incidence of diseases treated with warfarin would reveal useful data for audits concerning management of anticoagulant treatment. We aimed to assess warfarin treatment in primary health care with regard to prevalence, incidence, treatment diagnosis and patient characteristics.
\end{abstract}

Methods: A one-year retrospective study of electronic patient records up to May 2000 in primary health care in Stockholm, Sweden. Five primary health care centres with a registered population of 75 146. Main outcome measures were prevalence, incidence and treatment diagnosis.

Results: Five hundred and seven patients, mean age 71.9 years, were on warfarin treatment. The prevalence was $0.67 \%$ (age-adjusted $0.75 \%$ ), and it was significantly higher for men $(0.78 \%$ ) than for women $(0.58 \%)(p=0.01)$. In the age group $75-84$ years the prevalence was $4.54 \%$. The most prevalent treatment diagnosis was chronic atrial fibrillation $(0.28 \%)$, which was more predominant for males $(p=0.02)$, followed by cerebrovascular disease $(0.13 \%)$ and deep venous thrombosis $(0.13 \%)$. The yearly incidence of warfarin treatment was $0.17 \%$, with chronic atrial fibrillation as the predominant treatment diagnosis.

Conclusion: Warfarin treatment in primary health care is prevalent among the elderly. Chronic atrial fibrillation is the main treatment diagnosis. There is a gender difference favouring men in general and chronic atrial fibrillation as the treatment diagnosis.

\section{Background}

Oral anticoagulant drugs, i.e. vitamin $\mathrm{K}$ antagonists, have been shown in well-designed clinical trials to have antithrombotic effectiveness in a variety of disorders and conditions. They are effective in the prevention of venous thromboembolism, thrombosis on heart valve prostheses, embolic stroke in patients with chronic atrial fibrillation (CAF) and cerebrovascular disease [1], in patients with pulmonary embolism [2], and as secondary prophylaxis after myocardial infarction [3]. Warfarin is the standard oral anticoagulant drug used in Sweden. 
The indications for warfarin treatment in primary health care (PHC) are increasing [4,5]. It is well known that efficacy in clinical trials may be a poor guide to effectiveness in everyday clinical practice, and undertreatment with warfarin is reported for CAF [6], and can be suspected for other indications. Information on the occurrence (i.e. prevalence and incidence) of these diseases would reveal useful data for audits concerning management of anticoagulant treatment. The prevalence of warfarin treatment differed somewhat in earlier studies. In a Swedish study a prevalence of $0.52 \%$ was reported [7]. Several studies reveal that $\mathrm{CAF}$ is the most common treatment diagnosis $[5,8]$. However, these studies have not documented anticoagulation management in a representative sample of clinics. There is thus a need for generalisable data relating to warfarin treatment in everyday clinical practice in order to estimate and discuss the quantity and quality of warfarin treatment in PHC.

Warfarin has a narrow therapeutic range and requires frequent monitoring and dosage adjustment. The workload involved in anticoagulant treatment has grown $[9,10]$, and monitoring is increasingly managed by general practitioners (GP) $[7,11]$. It is well known that the number of bleeding and thromboembolic complications during treatment with oral anticoagulants is dependent on the indications for treatment.

Patients on warfarin treatment in Stockholm are now almost exclusively managed in PHC. Use of electronic patient records is presently almost universal among GPs in the area, providing us with clinical data that is useful for audits and research. A population registry is maintained for each GP, which makes it possible to calculate the total registered population for the PHC centres.

The objective of this study was to study warfarin treatment in everyday clinical practice in PHC with regard to prevalence, incidence, treatment diagnosis, and patient characteristics.

\section{Methods}

Selection of PHC centres

In order to get a representative sample, we invited five PHC centres from five different health care districts in Stockholm County, and all agreed to participate. In each PHC centre one GP was appointed as investigator. Each investigator retrieved information on all patients attending the PHC centre in question, regardless of who the responsible GP was. The total registered population (calculated from a population registry maintained for each GP) of the participating GPs comprised 75145 individuals at the end of the study period.

\section{Selection of patients}

The initial selection criterion included all patients on warfarin treatment during the 12-month study period (June 1999 up to May 2000). Eligible patients were further defined as patients who were monitored using prothrombin-time and whose daily dosages of warfarin were prescribed by a GP at the PHC centre. The electronic patient record systems were identified through their statistical modules in a primary data retrieval including age and gender. The investigator thereafter manually reviewed all these records.

Patients who had received a minimum of 30 consecutive days of treatment during the study period were included. In other words, patients on treatment at the start of the study period, patients starting treatment during the study period, and patients discontinuing treatment during the study period were included. All patients on treatment, as defined above, were considered eligible. The clearly and unambiguously determinable current indication or indications for treatment were listed for each patient.

\section{Statistical analysis}

The data were analysed using SPSS ${ }^{\circledR}$ software. Independent two-sample t-tests were used to compare interval scaled variables. The Chi-square test was used to test distribution of cross-classified nominal variables. Ninety-five percent confidence intervals (CI) were used.

\section{Ethical considerations}

This study was approved by the regional ethics committee at Karolinska Insitutet.

\section{Results}

Out of the registered population, 507 patients were on warfarin treatment. The mean age of these patients was 71.9 years, with a higher mean age of 74.7 for women and a mean age of 69.6 for men $(\mathrm{p}=0.002)$. The age distribution is shown in Table 1 . There was a statistically significant predominance of men overall $(\mathrm{p}=0.01)$ as well as in the age group 45-64 years $(\mathrm{p}<0.01)$, whereas women were predominant in the age group $85+(\mathrm{p}<0.01)$.

The overall prevalence for warfarin treatment was $0.67 \%$ (Table 1 ), with $0.78 \%$ in men and $0.58 \%$ in women. On standardizing by sex and age with regards to the whole Swedish population (in December 1999), this would give a prevalence of $0.75 \%(0.89 \%$ for men and $0.63 \%$ for women). The age group 75-84 years had the highest prevalence, which was $4.54 \%$. The most common treatment diagnosis was CAF (0.28\%), followed by cerebrovascular disease $(0.13 \%)$, deep venous thrombosis $(0.13 \%)$ and prosthetic valve $(0.12 \%)$. Men had CAF as a treatment diagnosis more frequently than women $(p=0.02)$. The 
Table I: Patients on warfarin treatment in a registered population of 75 I 46. Age and gender distribution and prevalence, presented as number of patients, percentage of patients, percentage of women and $95 \%$ confidence intervals $(\mathrm{Cl})$.

\begin{tabular}{ccccc}
\hline $\begin{array}{c}\text { Age and gender group } \\
\text { (years and gender) }\end{array}$ & Number of patients & $\begin{array}{c}\text { Percentages of patients (\%) } \\
(\mathrm{n}=507)\end{array}$ & $\begin{array}{c}\text { Prevalence (\%) } \\
(\mathrm{Cl})\end{array}$ & $\begin{array}{c}\text { Percentage of women (\%) } \\
\text { (\%) }\end{array}$ \\
\hline-44 & 17 & 3.4 & 0.04 & $35(10 ; 61)$ \\
$45-64$ & 99 & 19.5 & 0.53 & $26(17 ; 35)^{1}$ \\
$65-74$ & 143 & 28.2 & 4.80 & $44(36 ; 52)$ \\
$75-84$ & 203 & 40.0 & 2.54 & $49(42 ; 56)$ \\
$85+$ & 45 & 8.9 & 0.67 & $67(52 ; 81)^{2}$ \\
All ages & 507 & 100.0 & 0.78 & $44(40 ; 49)^{3}$ \\
Men & 282 & 55.6 & 0.58 & \\
Women & 225 & 44.4 & & \\
\hline
\end{tabular}

I significantly more men $(p<0.01) ;^{2}$ significantly more women $(p<0.01) ; 3$ significantly more men $(p=0.01)$

Table 2: Patients on warfarin treatment in a registered population of 75 I 46. Treatment diagnosis, prevalence and incidence, presented as number of patients and percentage.

\begin{tabular}{|c|c|c|c|c|c|c|}
\hline Treatment diagnosis & $\begin{array}{l}\text { Number of } \\
\text { patients }(n)\end{array}$ & Mean age & $\begin{array}{l}\text { Percentage of } \\
\text { women (\%) }\end{array}$ & $\begin{array}{l}\text { Percentage of the study } \\
\text { group }(\%)(n=507)\end{array}$ & Prevalence (\%) & Incidence (\%) \\
\hline Chronic atrial fibrillation & 211 & 73.8 & 42.22 & 41.6 & 0.28 & 0.07 \\
\hline Cerebrovascular disease & 96 & 74.5 & 47.9 & 18.9 & 0.13 & 0.02 \\
\hline Deep venous thrombosis & 96 & 69.4 & 42.1 & 18.9 & 0.13 & 0.05 \\
\hline Prosthetic valve & 89 & 70.1 & 42.7 & 17.6 & 0.12 & 0.01 \\
\hline Pulmonary embolism & 65 & 72.4 & 53.9 & 12.8 & 0.09 & 0.01 \\
\hline Peripheral artery disease & 14 & 80.8 & 50.0 & 2.8 & 0.02 & 0 \\
\hline Cardiac infarction & 10 & 75.4 & 60.0 & 2.0 & 0.01 & 0.01 \\
\hline Other indications & 31 & 71.6 & 45.2 & 6.1 & 0.04 & 0 \\
\hline Any diagnosis (all patients) & 507 I & 71.9 & 44.4 & 1001 & 0.67 & 0.17 \\
\hline
\end{tabular}

I not a sum, as 105 patients had more than one treatment diagnosis ${ }^{2}$ significantly more men $(P=0.02)^{3}$ significantly more men $(p=0.01)$

mean age in different groups of treatment diagnoses ranged from 69.4 years for deep venous thrombosis to 80.8 years for peripheral artery disease.

The number of patients who started treatment with warfarin (and continued for more than 90 days) at the participating PHC centres was 127, giving a yearly incidence of $0.17 \%$. The treatment diagnosis with the highest incidence was CAF (0.07\%) (Table 2).

\section{Discussion}

In this study we investigated warfarin treatment in PHC with the main focus on its occurrence and treatment diagnosis. We found it to be fairly common among the elderly, with a gender difference favouring males and dominated by CAF.

The prevalence and incidence for all treatment diagnoses of warfarin treatment in a registered population have received little attention, and differs somewhat in similar studies. In a Swedish study in 1997, an age-adjusted prev- alence of $0.88 \%$ ( $1.19 \%$ for men and $0.58 \%$ for women) was reported [7]. The figures in our study $(0.67 \%$, age-adjusted $0.75 \%$ ) were in line with that study, indicating that there is no increase. However, in a Finnish PHC study the reported age-adjusted prevalence was $0.65 \%$ [8]. There does not appear to be a pronounced increase, but as GPs are encouraged to consider warfarin treatment more frequently due to its suboptimal use, some increase would be expected. Maximising adherence with the guidelines on anticoagulant treatment seems to be increasingly important to primary care providers. Numerous constraints probably influence this, such as organisational problems, reimbursement issues, as well as issues related to the GPs and the patients.

The gender difference in our study was also found in a similar study [7], but in Finnish PHC no difference was found [8]. This could be explained by the higher ages of the females and a different distribution of treatment diagnoses, but it could also reveal a real gender bias regarding adherence to guidelines. Such gender differences are 
found in the management of other diseases such as chronic heart failure [12].

Prevalence figures are often not based on a registered population, as in our study, but rather on the population in a geographical area, and this constitutes an advantage of our study. Further, most studies on anticoagulant treatment are not based on PHC, with a representative sample of patients from everyday clinical practice. There is no reason to believe that patients on warfarin treatment were missed, since all patients on treatment (as defined above) at the PHC centres are registered under prothrombin-time values in the laboratory module of the record systems. However, there are probably a few patients on warfarin treatment who have never been in contact with a GP, and the prevalence may have been underestimated.

The indications for warfarin treatment in PHC were in line with those in some similar studies [4,5], but the figures for CAF were somewhat higher in our study. The treatment diagnosis, in terms of the reason for treatment, can be discussed, as a large proportion of the patients have more than one, and selecting one of several diagnoses as the main treatment diagnosis can be questionable. The high figure for CAF in our study is due in part to the fact that it is frequently a concurrent treatment diagnosis.

Further research is needed on the management of all patients with diseases with indications for anticoagulant treatment regarding pharmacological treatment and other clinical information. For example, it would also be of interest to study non-warfarin treated patients with CAF. However, this would require reliable ways of identifying these patient groups in the electronic patient record systems.

Given the frequent monitoring and dosage adjustments, there is a significant workload in warfarin treatment in PHC in Sweden. An increasing number of patients in the Stockholm area have already been referred to PHC, as has been suggested [6]. A future increase can nevertheless be expected, and this may require an organised approach to anticoagulant management including computer dosing systems and improved systems for follow-up.

\section{Conclusions}

Warfarin treatment in PHC is common among the elderly. $\mathrm{CAF}$ is most common treatment diagnosis. There is a gender difference favouring men in general and CAF as the treatment diagnosis.

\section{Competing interests}

The study was supported by grants from the Stockholm County Council and AstraZeneca Sverige AB. IB is a health economist at the AstraZeneca Sverige AB.

\section{Authors' contributions}

GHN participated in the design and coordination of the study, performed the statistical analysis and drafted the manuscript. IB participated in the design and coordination of the study and drafted the manuscript. HJ participated in the design of the study and drafted the manuscript. All authors read and approved the final manuscript.

\section{Acknowledgements}

We thank all the GPs who participated in the study. We also thank Ingvar Krakau, MD, PhD, who participated in the design of the study.

\section{References}

I. Hart RG, Sherman DG, Easton JD and Cairns JA Prevention of stroke in patients with nonvalvular atrial fibrillation Neurology |998, 5 |:674-68|

2. Bick RL Proficient and cost-effective approaches for the prevention and treatment of venous thrombosis and thromboembolism Drugs 2000, 60:575-595

3. Verheugt FW Warfarin for ischemic heart disease Cardiol Rev 200I, 9:325-328

4. Jansson JH, Westman G, Boman K, Nilsson T and Norberg B Oral anticoagulant treatment in a medical care district - a descriptive study Scand J Prim Health Care 1995, I3:268-274

5. Wändell PE Anticoagulant treatment of patients in Swedish primary health care Eur J Clin Pharmacol 200I, 57:6I-64

6. Lip GY, Golding DJ, Nazir M, Beevers DG, Child DL and Fletcher RI A survey of atrial fibrillation in general practice: the West Birmingham Atrial Fibrillation Project Br J Gen Pract 1997, 47:285-289

7. Wändell PE Anticoagulant patients in Swedish primary health care. A comparison 5 years apart Scand J Prim Health Care 1998, I 6: 183-187

8. Eskola K, Aittoniemi P, Kurunmaki H, Latva-Nevala A, Paloneva M and Wallin AM Anticoagulant treatment in primary health care in Finland Scand J Prim Health Care 1996, I4:165-170

9. Taylor FC, Ramsay ME, Renton A and Cohen H Methods for managing the increased workload in anticoagulant clinics $B M$ J 1996, 3 | 2:286

10. Kalra L, Yu G, Perez I, Lakhani A and Donaldson N Prospective cohort study to determine if trial efficacy of anticoagulation for stroke prevention in atrial fibrillation translates into clinical effectiveness BMJ 2000, 320:1236-1239

II. Azar AJ, Deckers JW, Rosendaal FR, van Bergen PF, van der Meer JF and Jonker J $\mathrm{J}$ Assessment of therapeutic quality control in a long-term anticoagulant trial in post-myocardial infarction patients Thromb Haemost 1994, 72:347-351

12. Mejhert $M$, Holmgren J, Wändell P, Persson $H$ and Edner M Diagnostic tests, treatment and follow-up in heart failure patients is there a gender bias in the coherence to guidelines? Eur J Heart Fail 1999, I:407-10

\section{Pre-publication history}

The pre-publication history for this paper can be accessed here:

http://www.biomedcentral.com/1471-2296/4/3/prepub 